\title{
Opinions of Nurses/Midwives on Transition of Nursing Education from Hospital Base to University in Nigeria
}

\author{
Dandong, Mary samuel ${ }^{1}$ David, Lungcit Shalkur ${ }^{2}$ Williams, Jonathan Manja ${ }^{2}$ \\ Attah, Esther Shahai ${ }^{2}$ \\ ${ }^{\text {I}}$ (School of Midwifery, Vom, Plateau State) \\ ${ }^{2}$ (School of midwifery, Jos, Plateau state) \\ ${ }^{2}$ (School of Nursing, Vom. Plateau State) \\ ${ }^{2}$ (Primary health care agency, Ministry of Health, Lafiya, Nasarawa state)
}

\begin{abstract}
Objective: Globally, the predominant trend in nursing education over the last century has been towards greater professionalization through the lengthening of training periods and the shift from a hospital-based apprenticeship model of professional education to institutions of higher learning. The study sought the opinion of academic and hospital nurses in Jos, Plateau state on the ongoing transition in nursing education from hospital base to the University, having four objectives as a guide.

Methods: A cross-sectional descriptive survey design was adopted for the study and a stratified sampling technique was used to recruit 74 nurses/midwives. Descriptive statistics was generated for demography and opinions of nurses/midwives while inferential statistics (student's t-test) was used to investigate their opinions with their practice area.
\end{abstract}

Results: Study findings revealed high level of acceptance of the transition process in nursing education among nurses, who also believed that the transition is of great benefits to the profession, the professionals and patients. Findings also revealed that respondents believed the benefits of the transition outweigh the challenges.

Conclusion: it was concluded that nurses believed in the transition process and perceived greater benefits.

\section{Introduction}

In recent years, an important global development in the professionalization of nursing education has been the call for a university degree as the minimum requirement for entry to the profession [1]. In line with this trend the National Universities Commission (NUC) released a list of 21 Universities approved/accredited for nursing degree programmes as at $16^{\text {th }}$ February 2012, of which University of Jos is on the list [2]. The hospital base nursing education still exists in Nigeria together with the greater emphasis and accreditation of Nigerian Universities to provide degree education and training for nurses. It is thought that this transition from hospital base nursing education to the University in Nigeria can be challenging particularly to nurses/midwives themselves but there is scarcity of information with regards to nurses/midwives opinions regarding the transition in nursing education in Nigeria. This study sought to assess the acceptance and other opinions related to the transition in nursing education from hospital base to the university among academic and hospital nurses/midwives in Jos, Plateau State. Findings gathered by this study can help relevant design and implement research based strategy effective in seamless transition in nursing education in Nigeria from hospital base to the university.

\section{Study Design}

\section{Materials and Methods}

A cross sectional descriptive survey design was employed for this study. This design was used to elicit data from respondents that were relevant to the study objectives.

\section{Population and Sample Selection Procedures}

The target population for the study was academic and hospital nurses and the accessible population was nurses/midwives lecturing and working in Schools of Nursing/Midwifery, Jos and Plateau State Specialist Hospital Jos respectively. Inclusion criteria were all nurses in the study areas who were present within the period of study and who consented to participate while the exclusion criterion was those nurses/midwives who were absent at the study areas within the period because of leave or other reasons. At the time of study there were 186 and 24 nurses/midwives in Plateau State Specialist Hospital and Schools of Nursing/Midwifery Jos respectively. Using a precision of \pm 10 , a sample size of 70 was estimated using published sample size table (3). The study population was stratified into two: academic and hospital practice area, and 20 and 54 respondents were recruited respectively based on proportionate size of sampling frame from each practice area. 


\section{Instrument}

The instrument used for data collection was a self- completion questionnaire developed by the researchers from related literatures [4], [5]. The questionnaire consisted of two major parts: demography and transition in nursing education-related items. The later part had 4 sections and contained both open and close ended questionnaire items relevant to the study objectives. The questionnaire was presented to experts in the Faculty of Education, University of Jos for content and relevances. Also, the reliability of the questionnaire was estimated using Cronbach's alpha coefficient. This test indicates the consistency of responses to all knowledge test items in the questionnaire. The possible score for Cronbach's alpha coefficient ranges from 0-1. A score of 0.7 or above is acceptable for survey works [6].

\section{Ethical Consideration}

Ethical clearance and approval for this work was obtained from the Ethics and Research Committee of Plateau State Specialist Hospital Jos, Plateau State with reference number PSSH/ADM/ETH.CO/2016/009. Respondents' oral consent was sought before participation in the survey. Also, their identity was not required in filling the questionnaires.

\section{Data Analysis}

The data generated from the study were analyzed with the aid of Statistical Package for Social Sciences (SPSS) version 20. Frequency and percentage were generated for respondents' demography while mean \pm standard deviation was computed for opinions of the respondents related to acceptance, benefits, challenges, and ways of harnessing the nursing education. The possible score for each item was $1-5$ with strongly disagree having 1 to strongly agree having 5. Mean values greater than 3 suggests agreement item or domain as the case may be and vice versa. Inferential statistics (student T test) was used to investigate association of respondents' opinions with their work place with $p$ value less 0.05 used for significance. Open-ended questionnaire items were analyzed qualitatively by searching for common themes in respondents' textual responses.

\section{Results}

All the 74 questionnaires were filled and returned giving a response rate of $100 \%$ as the researchers did not give it to those who declined to participate in the survey. The reliability of the filled questionnaires as estimated by Chronbach's alpha coefficient was 0.84 indicating strong internal consistency.

The demographic characteristics of study respondents are shown in Table 1. Most of the respondents (45.8\%) were within the age category of $\geq 41$ years and had RN/RM as their highest qualification (41.7\%). More than half of respondents were females (52.8) and had been practicing for more than 10 years $(55.5 \%)$ with about three-quarter working in the hospital $(70.8 \%)$.

Table 1: Demographic characteristics of study respondents $(n=74)$

\begin{tabular}{|l|l|l|}
\hline Variable & Frequency & Percentage \\
\hline Age category (in years) & & \\
\hline $20-30$ years & 3 & 4.2 \\
\hline $31-40$ years & 32 & 44.4 \\
\hline 41 and above & 33 & 45.8 \\
\hline Gender & & \\
\hline Male & 27 & 37.5 \\
\hline Female & 38 & 52.8 \\
\hline Highest Professional Qualification & & \\
\hline RN & 14 & 19.4 \\
\hline RM & 3 & 4.2 \\
\hline RN/RM & 30 & 41.7 \\
\hline BNSC & 19 & 26.4 \\
\hline Others & 2 & 2.8 \\
\hline Years of Practice & & \\
\hline$<10$ & 31 & 43.1 \\
\hline $11-20$ & 23 & 31.9 \\
\hline$>20$ & 17 & 23.6 \\
\hline Area of Practice & & \\
\hline Hospital & 51 & 70.8 \\
\hline Education & 20 & 27.8 \\
\hline
\end{tabular}

Cumulative $\%<100$ for any subgroup was due to non-response

Prevalence of respondents' acceptance of the transition in nursing education from hospital base to the university is shown in Table 2. More than 8 out of every 10 respondents $(84.7 \%)$ were aware of the transition in nursing education while about 7 out of every 10 were comfortable $(68.1 \%)$ with the transition. 
Table 2: Acceptance of Transition in Nursing Education $(\mathrm{n}=74)$

\begin{tabular}{|l|l|l|}
\hline Variable & Frequency & Percentage \\
\hline Aware of the transition in Nursing education from hospital base to the University & & \\
\hline Yes & 61 & 84.7 \\
\hline No & 5 & 6.9 \\
\hline Comfortable with the transition programme in Nursing education & & \\
\hline Yes & 49 & 68.1 \\
\hline No & 13 & 18.1 \\
\hline
\end{tabular}

Cumulative \% < 100 for any subgroup was due to non-response

Respondents who accepted transition in Nursing Education from hospital base to university gave supporting reason related to improvement in nursing education and associated knowledge, skills and confidence in the nurses so trained. For example, some of their texts captured these as:

"It will lead to increase quality of education and training",

'It will increase nursing education in Nigeria to be at par with global standards'. Others supported the transition with reasons related capacities of graduate nurses to engage in nursing research and application of scientific evidence-base practice as illustrated below:

'It will enable graduate nurses to have research skills',

'It will enable acquisition of scientific base knowledge, and skills for quality nursing service'.

Those who opposed the transition in nursing education from hospital base to the University cited the slow and inconsistency in the university calendar, lack of standardized transition format, fear of producing nurses less competent in basic nursing skills, and poor funding of university education. Some of their related texts were:

"the calendar system in the University is slow"

"'there is inconsistency in university training calendar",

'there is no standardized workable format for transition agreed upon by Nursing and Midwifery Council of Nigeria (N\&MCN) and National University Commission (NUC)',

"'the transition is not according to globally accepted standards"'

"'there is poor funding of university education",

"There will be overcrowding in the university",

Table 3 shows the mean score of respondents' opinion on the benefits of the transition to the profession. Items with higher agreement by the respondents were: 'there will be authorization of institutions by relevant organs of the federal Government to award academic certificates' (3.42 \pm 0.60$)$, 'there will be smooth academic progression of students along existing educational system' ( $3.42 \pm 0.60)$, 'it will results in meeting the more sophisticated demands of today's patient care' $(3.33 \pm 0.72)$ and 'there will be higher proficiency in ability to make nursing diagnoses $(3.33 \pm 0.58)$. Item with the least agreement score was 'There will be an improved problem solving skills' $(2.51 \pm 0.97)$. The overall mean score for the benefits scale was $3.21 \pm 0.41$ (mean \pm standard deviation)

Table 3 Benefits of the Transition Programme

\begin{tabular}{|l|l|}
\hline Item & Scoring (Mean \pm SD \\
\hline $\begin{array}{l}\text { There will be authorization of institutions by relevant organs of the federal } \\
\text { Government to award academic certificates }\end{array}$ & $3.42 \pm 0.60$ \\
\hline $\begin{array}{l}\text { There will be smooth academic progression of students along existing educational } \\
\text { system }\end{array}$ & $3.39 \pm 0.73$ \\
\hline It will results in meeting the more sophisticated demands of today's patient care & $3.33 \pm 0.72$ \\
\hline There will be an improved critical thinking skills & $3.19 \pm 0.72$ \\
\hline There will be improvement in leadership skills & $3.32 \pm 0.72$ \\
\hline There will be higher proficiency in ability to make Nursing Diagnosis & $3.33 \pm 0.58$ \\
\hline There will be higher proficiency in evaluating Nursing interventions & $3.14 \pm 0.64$ \\
\hline There will be stronger communication skills & $3.12 \pm 0.76$ \\
\hline There will be an improved problem solving skills & $2.51 \pm 0.97$ \\
\hline Total & $3.21 \pm 0.41$ \\
\hline
\end{tabular}

Benefits of transition in nursing education from hospital base to the university identified by respondents were related to better inter-professional relationship, quality of patient care and public perception of nurses. Some of the specific statements include:

"'it will increase nurses' confidence in collaborative relationship with other healthcare professionals"

"it will decrease inter-professional conflict"

"'It will reduce nurse marginalization in Nigerian healthcare systems", 
"it will enable nurses to be politically oriented and educationally sound"

" it will enable nurse to offer evidence-based and holistic care to patients"

Table 4 shows the mean score of respondents' response on the challenges of the transition process. The overall score for the challenge scale was $2.48 \pm 0.68$. None of the item was identified as a challenge to the transition of nursing education from hospital base to the University as all items had mean scores of $<0.3$.

Table 4: Challenges of the Transition Process $(n=74)$

\begin{tabular}{|l|l|}
\hline Item & $\begin{array}{l}\text { Scoring } \\
\text { (Mean } \pm \text { SD }\end{array}$ \\
\hline There is shortage of academic staff & $2.60 \pm 0.95$ \\
\hline There is poor funding of nursing education & $2.50 \pm 1.08$ \\
\hline clinical facilities are not upgraded to have enriched experience according to international standard & $2.51 \pm 1.04$ \\
\hline There is difficulty in maintain high professional standard with regards to nursing skills & $2.48 \pm 1.09$ \\
\hline There is reduced professional discipline & $2.52 \pm 0.91$ \\
\hline There is inadequate workforce planning & $2.28 \pm 1.07$ \\
\hline $\begin{array}{l}\text { There is inability to upgrade nursing education curricula that will impact relevant competencies needed } \\
\text { to meet the future needs of patient and academic progression }\end{array}$ & $2.42 \pm 0.99$ \\
\hline $\begin{array}{l}\text { There are competing priorities relevant to multiple role responsibility affecting interest of nurses to } \\
\text { upgrade their education }\end{array}$ & $2.35 \pm 0.95$ \\
\hline Total scores & $2.48 \pm 0.68$ \\
\hline
\end{tabular}

Respondents identified lack of infrastructure for clinical skills development in university, lack of mentors, lack of resources, and competing family needs (especially for married nurses already with RN/RM) as challenges to transition in nursing education from hospital base to university. Some of their specific statements were:

"university training lack emphasis and facility for clinical basic nursing skills"

"It will produce nurses with poor clinical skills"

"lack of ICT facility"

"'antagonism and lack of support from older colleagues for junior pursuing nursing degree",

" 'competing educational needs of children/spouse for married nurses already with RN/RM"'

Table 5 shows the mean score of respondents' opinion on ways of harnessing nursing education. The overall score for the scale was $2.38 \pm 0.90 \mathrm{y}$ while items with high scores were: 'encourage on-line and distant learning for hospital trained nurses to earn a degree' $(2.43 \pm 1.00)$, 'design a degree programme lasting 12 to 24 months for hospital based trained nurses' $(2.42 \pm 0.97)$, release and sponsor registered nurses to earn a degree' $(2.40 \pm 1.04)$ and have a deadline for hospital trained nurses to earn a degree' $(2.33 \pm 1.04)$.

Table 5: Ways of Harnessing Nursing Education $(\mathrm{n}=74)$

\begin{tabular}{|l|l|}
\hline Item & Scoring (Mean \pm SD \\
\hline There should be a dead line to phase out hospital based nursing education & $2.30 \pm 1.01$ \\
\hline Make entry into nursing strictly BNSc & $2.31 \pm 1.07$ \\
\hline Design a degree programme lasting 12 to 24 months for hospital based trained nurses & $2.42 \pm 0.97$ \\
\hline $\begin{array}{l}\text { Requirement for a degree should be made to be 2 years working experience and RN certificate in } \\
\text { addition to the 'o' level requirements for hospital trained nurses. }\end{array}$ & $2.30 \pm 0.95$ \\
\hline Encourage on-line and distant learning for hospital trained nurses to earn a degree & \\
\hline Have a deadline for hospital trained nurses to earn a degree & $2.43 \pm 1.00$ \\
\hline Release and sponsor registered nurses to earn a degree & $2.33 \pm 1.04$ \\
\hline Total & $2.40 \pm 1.04$ \\
\hline
\end{tabular}

Respondents opined that the way forward in transition in nursing education from hospital base to university was to design a special program for nurses with RN/RM and other specializations to earn a university degree in nursing. Some of the texts captured this as:

"nurses with diploma and/or specializations should only spend 12 months in the university to earn a degree in nursing",

"there should be university part-time program for nurses already with RN/RM"

"More nurses should be employed so as to create space for those with RN/RM to earn degree in the university"

"encourage bed side nurses to go for further studies"

Others viewed increase capacity in the university to admit nursing students as the way forward:

"Nursing degree program should be introduced in all Nigerian universities"

"degree in Midwifery should be started in Nigerian universities"

"increase funding of university education" 
Table 6 shows results for association of respondents' mean score for each domain with their area of practice. Respondents in academic practice scored better than their counterpart in the hospital for benefits of the transition in nursing education but the difference was not statistically significant $(P=0.240)$. There were significant differences in their mean scores for challenges of transition and ways of harnessing nursing education $(P=0.006$ and $P=0.015$ respectively).

Table 6: Association between Opinion of Nurses and Practice Area

\begin{tabular}{|l|l|l|l|}
\hline Variables & Hospital Nurses & Academic Nurses & $\boldsymbol{P}$ Value \\
\hline $\begin{array}{l}\text { Benefits of the transition } \\
\text { process }\end{array}$ & $3.17 \pm 0.08$ & $3.31 \pm 0.40$ & 0.240 \\
\hline $\begin{array}{l}\text { Challenges of the transition } \\
\text { process }\end{array}$ & $2.63 \pm 0.64$ & $2.10 \pm 0.65$ & $\mathbf{0 . 0 0 6}$ \\
\hline $\begin{array}{l}\text { Ways of harnessing nursing } \\
\text { education }\end{array}$ & $2.53 \pm 0.91$ & $1.93 \pm 0.71$ & $\mathbf{0 . 0 1 5}$ \\
\hline $\begin{array}{l}\text { Bold } \boldsymbol{P} \text { value indicates significant difference in mean score between hospital and academic } \\
\text { nurses/midwives for item }(\boldsymbol{P}<\mathbf{0 . 0 5})\end{array}$ \\
\hline
\end{tabular}

\section{Discussion}

This study sought to assess the level of awareness and the acceptance of the transition in nursing education from hospital base to university among nurses/midwives in study sites and found both awareness and acceptance levels to be high ( $84.7 \%$ and $68.7 \%$ respectively). This level of acceptance is very encouraging and needed for the realization of the proposed reforms of nursing education in Nigeria [7].

Nurses/midwives in the study sites are of the opinion that the transition in nursing education in Nigeria from hospital base to university education is beneficial as adjudged by their mean score of greater than 3 . Specifically they hold that the transition will bring about authorization of institutions by relevant organs of the federal government to award academic certificate and also will result to a smooth academic progression of students along existing educational system; bring about higher proficiency in nurses/midwives ability to make nursing diagnosis, and enhance meeting the more sophisticated demands of today's patients care. These findings concur with the statement made by [8] when she listed the benefit of the transition in nursing education to include authorization of the institution by relevant organ of the federal government to award academic certificate and the smooth academic progression of students along existing educational system. A study published in the journal of the American Medical Association (JAMA) demonstrated that surgical patients have a substantial survival advantages if treated in hospital with higher proportions of nurses educated at the degree level [4]. Other benefits of nursing education transition identified in this study not scarcely reported by prior works include the perception that university training of nurses/midwives enhance better inter-professional relationship and better public perception of nurses.

The study also sought the opinion of respondents on the challenges of the transition process and found that their perception of challenges was positive as evidenced by a mean score $<3$ for the entire challenge scale and individual items .Relatively, the study population identified shortage of academic staff, potential for reduced professional discipline, and poor clinical facilities for enriched experience according to international standard as challenges for nursing education transition to the university. This agrees with the findings by [5] who identified lack of capacity as a barrier needed to ensure a nursing workforce that is $80 \%$ degree prepared. Also ,the $\mathrm{N} \& \mathrm{MCN}$ listed some of the identified as challenges of the transition process except for the perception that it may reduce professional discipline.

This study also identified competing educational needs of children/spouse for married nurses already with RN/RM certificate is a barrier to the transition process. This is finding is similar to prior reported by [9] who in addressing barriers to completing nursing degree, discovered that competing priorities relative to multiple role responsibilities left little time and energy for nurses to devote time to their education.

The fourth objective was to identify ways in which nursing education can be harnessed in support of transition to university education. The study population is of the view that encouraging on-line and distant learning programme for hospital trained nurses to earn a degree within 12 to 24 months, releasing and sponsoring registered nurses to earn a degree and also having a deadline for hospital nurses to earn a degree are ways of harnessing nursing education. All these concur with suggestions made by [10] on the ways of harnessing nursing education. Other ways to harness the transition identified by the study population include introducing nursing degree in all universities in Nigeria and employing more nurses so as to reduce work load for nurses to pursue degree nursing education.

In conclusion, this study found high acceptance of the transition of nursing education from hospital base to the university. Perceived benefits of the transition include better training of the nurse/midwife for proficiency; enhance inter-professional relationship, better public perception of public status of nurse/midwife, and better quality service delivery to client. Some of the identified challenges and barriers to the transition include fear of decline in intra-professional discipline and conduct and poor human, capital, and physical 
facilities for university nursing education in line with international standards. Setting and monitoring time frame for all hospital base trained nurses/midwives to acquire university education, supporting all Nigerian universities to run nursing degree programmes, and providing on-line and distant degree programme for hospital base trained nurses/midwives to pursue university nursing degree were the ways identified for harnessing the transition of nursing education from hospital base to the university.

\section{Recommendations}

Based on the findings of this study, the following are recommended:

1. Nursing and Midwifery Council should set up a committee to evaluate the progress of the transition process as this will help identifying new and persistent challenges.

2. All employers of nurses should release and sponsors nurses for degree programmes, also all Nigerian universities should introduce nursing degree programmes such as online and part time programmes that will last not more than 24 months for hospital trained nurses so as to accommodate more nurses that will be released and sponsored.

3. National Association of Nigerian nurses and midwives (NANNM) should embrace and work alongside Nursing and Midwifery Council in ensuring a dead line for all hospital trained nurses to earn a degree.

4. N\&MCN and NANNM should ensure professional discipline and standard are maintained even in the midst of the transition process by introducing hospital based apprenticeship, that is, nursing students receiving training in the university should move to the hospital setting from the fourth year of training, and adapt the pattern used for hospital trained nurses.

5. Nurses at all levels should be active participants in the transition process by making deliberate effort to earn a degree (for those without a degree) and imbibe the spirit of professional mentorship.

\section{References}

[1]. D. Blaauw, P. Ditlopo \& L. C. Rispel, Nursing education reforms in South Africa-lesson from a policy analysis study, Global Health action 2014. Retrieved from www.ncbi.nlm.gov/pubmed/25537941

[2]. Nursing World Nigeria, NUC released list of 21 universities approved /accredited for nursing programmes, 2012. Retrieved 17/10/2016 from www.nursingworldNigeria.com

[3]. I.D. Glean, Sampling, the evidence of extension programme impact, programme evaluation and organizational development. IFAS, University of Florida DEOD-5, 1992. www.sut.ac.th/lm/data/read6.pdf. retrieved on 17/10/2016

[4]. C. Delani \& B. Piscopo, Nurses experience in transition from RNS to BSNs. Journal of professional nursing 23(3): 2007, 167-73. Retrieved from http:/www.researchgate.net/publication/6296617, on $13^{\text {th }}$ August, 2016

[5]. C.T. Korner, \& M. Djukic, The nursing career process from the application through the first 2 years of employment. Journal of professional Nursing 25(4), 2009, $197-209$.

[6]. L. J. Cronbach, Coefficient alpha and the internal structure of tests. Psychometrika; (16), 1951, $297-334$

[7]. Nursing and Midwifery Council Newsletter, Proposed nursing education reforms. Nursing and midwifery council Nigeria (N\&MCN) Newsletter, 13(6), 2006, 4-7.

[8]. S. Bolaji, Benefits of nursing education reforms, Pharmanewsonline, $2016 . \quad$ Retrieved from www.pharmanewsonline.com/nursingcouncillistsbenefits-of-nursing-education-reforms.

[9]. C. Delani \& B. Piscopo, RN-BSN programmes: associate degree and diploma nurses perception of the benefits and barriers of returning to school. Journal for nurses in staff development. JNSD 20(4), 2004), 157-61.

[10]. D.O. Adeaga, RN-BSN upgrade for Nigerian nurses: suggested solutions: Suggested solutions, Nursing world Nigeria, 2012. Retrieved from www.nursingworldnigeria 